\title{
A case-control study of non-T cell acute lymphoblastic leukaemia of children in Hokkaido, Japan
}

\author{
MOTOI NISHI AND HIROTSUGU MIYAKE \\ From the Department of Public Health, Sapporo Medical College, Sapporo, Japan.
}

\section{ABSTRACT}

Study objective: The purpose of the study was to investigate factors associated with the occurrence of childhood acute lymphoblastic leukaemia in cases identified as of non-T cell type, stage I-IV.

Design: The study was a case-control investigation. Data were obtained by interview with parents of cases and controls.

Setting: The study was community based and was carried out in Hokkaido, Japan.

Subjects: 63 cases were identified. Controls (two for each case) were matched for sex, age and place of residence.

Measurements and main results: In univariate analysis, BCG vaccination, measles infection, measles vaccination, atopy, hip $\mathrm{x}$ ray, and milk intake of mother during pregnancy had significantly low odds ratios (ie, were less likely to be associated with leukaemia), while dental $\mathrm{x}$ rays for carious teeth and contact with animals at time of diagnosis had high odds ratios (more likely to be associated with leukaemia). In conditional logistic regression analysis employing these seven factors, measles infection/vaccination, $B C G$, atopy and dental $x$ ray remained significant.

Conclusions: Leukaemia subtypes are likely to have specific aetiologies. Future epidemiological research in leukaemia should take this into account.

At present acute lymphoblastic leukaemia is thought to be heterogeneous in origin, ie, composed of subclasses derived from various differentiating stages. $^{12}$

Many reports have referred to supposed aetiologies or risk factors for leukaemia. However most of these have considered leukaemia without discussing the immunological heterogeneity or differentiating stages of the disease. We have now carried out a case-control study of non-T cell acute lymphoblastic leukaemia in children whose immunological natures were determined by monoclonal antibodies.

\section{Methods}

\section{SELECTION OF CASES}

From November 1986 to October 1987, one of the authors (MN) had face to face interviews with the biological mothers of all the children with immunologically ascertained non-T cell acute lymphoblastic leukaemia who were in admission or were receiving regular outpatient treatment in nine hospitals in Hokkaido Prefecture (Sapporo National Hospital, Sapporo Medical College Hospital,
Hokkaido University Hospital, Sapporo Municipal Hospital, Tomakomai Oji Hospital, Obihiro Kosei Hospital, Obihiro Kyokai Hospital, Kushiro Rosai Hospital and Kitami Red Cross Hospital). There were a total of 63 eligible cases of leukaemia of this type. The 63 patients ( 32 males and 31 females) were diagnosed between 1981 and 1987. Approximately $80 \%$ of them ( 50 cases) were diagnosed after 1984 , and the median year of diagnosis was 1986. Their ages at diagnosis ranged from 0 to 14 years. All were Japanese.

These 63 cases had negative $T$ cell markers such as $E$ rosette and positive Ia antigen, with positive/negative CD10, CD19, or CD20. Such patients have previously been classified as "non-T non-B ALL" and they correspond to stage I-IV of the classification of non-T cell acute lymphoblastic leukaemia by Nadler $e t$ al. ${ }^{1}$

Children with $\mathrm{T}$ cell acute lymphoblastic leukaemia, who have been reported to account for only $11.7 \%$ of the cases, ${ }^{3}$ were not studied because they form a small minority.

\section{SELECTION OF CONTROLS}

Controls were matched with the index cases for age 
and sex, and for district of residence at the time of the index diagnosis. They were identified at visits for routine health examinations at health centres and hospitals located in the areas where the index cases lived. Their biological mothers were interviewed face to face by one of us (MN) between March and November 1987. Two controls were selected for each case, giving a total of 126 controls. All were Japanese. In Japan $80-90 \%$ of children are taken for health examinations, ${ }^{4}$ so these controls were considered to be a reasonable sample of the population.

Odds ratios were calculated using the method of Mantel and Haenszel. ${ }^{5}$ Ninety five percent confidence intervals $(\mathrm{CI})$ were calculated using the method of Breslow and Day. ${ }^{6}$

\section{Results}

The items with significantly low odds ratios $(\mathrm{p}<0.05$, 63 triplets) were:

(1) BCG vaccination in child before diagnosis.

(2) Measles or measles vaccination in child before diagnosis.

(3) Atopic diathesis (ie, history of asthma or atopic dermatitis) in child before diagnosis.

(4) Hip joint $x$ ray examination before diagnosis.

(5) Mother drank milk during pregnancy on at least one day per week.

The items which revealed significantly high odds ratios ( $p<0.05,63$ triplets) were:
(1) Dental $\mathrm{x}$ rays for carious teeth taken before diagnosis (more than one film).

(2) Keeping animals (pets or farm animals) at time of diagnosis.

The seven significant factors mentioned above were investigated further by dividing the entire group into the subgroups from 0 to 2 years of age (16 triplets), from 3 to 6 years of age ( 25 triplets), and from 7 to 14 years of age (22 triplets) (table 1).

Conditional logistic regression analysis ${ }^{7}$ was also applied to the entire group, employing these seven factors. BCG, measles or measles vaccination, atopy, and dental $\mathrm{x}$ ray remained significant (table 2).

Table 2 Relative risk ( $R R$ ) and 95\% CI of the seven factors by conditional logistic regression analysis for the entire group.

\begin{tabular}{lll}
\hline Factor & $R R$ & $95 \% C I$ \\
\hline BCG & $0 \cdot 1^{*}$ & $0 \cdot 0-1 \cdot 0$ \\
$\begin{array}{l}\text { Measles or measles } \\
\text { vaccination }\end{array}$ & $0.2^{*}$ & $0 \cdot 1-0.7$ \\
$\begin{array}{l}\text { Atopic diathesis } \\
\text { Hip joint x ray } \\
\text { examination }\end{array}$ & $0.3^{*}$ & $0 \cdot 1-0.8$ \\
$\begin{array}{l}\text { Milk intake during } \\
\text { pregnancy }\end{array}$ & 0.9 & $0.9-1 \cdot 3$ \\
$\begin{array}{l}\text { Dental x ray film } \\
\text { Contact with animals at } \\
\text { time of diagnosis }\end{array}$ & 2.5 & $0.8-1 \cdot 1$ \\
\hline p & $1.4^{*}$ & $1.0-2.0$ \\
& & $0.8-8.2$ \\
\end{tabular}

Table 1 Odds ratios (95\% CI, or case\%/control\% when 0 or $\infty$ ) of significant factors in univariate analysis.

\begin{tabular}{|c|c|c|c|c|}
\hline \multirow[b]{2}{*}{ Factor } & \multirow[b]{2}{*}{$\begin{array}{l}\text { Entire group } \\
\text { (63 triplets) }\end{array}$} & \multicolumn{3}{|l|}{ Subgroup } \\
\hline & & $\begin{array}{l}0-2 \text { years } \\
(n=16)\end{array}$ & $\begin{array}{l}3-6 \text { years } \\
(n=25)\end{array}$ & $\begin{array}{l}7-14 \text { years } \\
(n=22)\end{array}$ \\
\hline$\overline{\text { BCG }}$ & $\begin{array}{l}0.26^{*} \\
(0.09-0.78)\end{array}$ & $\begin{array}{l}0.33 \\
(0 \cdot 03-4 \cdot 16)\end{array}$ & $\begin{array}{l}0.07^{*} \\
(0.01-0.58)\end{array}$ & $\begin{array}{l}1 \cdot 50 \\
(0 \cdot 16-14 \cdot 4)\end{array}$ \\
\hline $\begin{array}{l}\text { Measles or } \\
\text { measles vaccination }\end{array}$ & $\begin{array}{l}0 \cdot 24^{*} \\
(0 \cdot 10-0 \cdot 60)\end{array}$ & $\begin{array}{l}0.14^{*} \\
(0.03-0.69)\end{array}$ & $\begin{array}{l}0 \cdot 17 \\
(0 \cdot 19-2 \cdot 74)\end{array}$ & $\begin{array}{l}0^{*} \\
(82 / 100)\end{array}$ \\
\hline $\begin{array}{l}\text { Atopic } \\
\text { diathesis }\end{array}$ & $\begin{array}{l}0.26^{*} \\
(0 \cdot 11-0.59)\end{array}$ & $\begin{array}{l}0.25 \\
(0.02-3.03)\end{array}$ & $\begin{array}{l}0.18^{*} \\
(0.05-0.64)\end{array}$ & $\begin{array}{l}0.39 \\
(0 \cdot 11-1 \cdot 30)\end{array}$ \\
\hline $\begin{array}{l}\text { Hip joint } \\
x \text { ray }\end{array}$ & $\begin{array}{l}0.25^{*} \\
(0.09-0.70)\end{array}$ & $\begin{array}{l}0.67 \\
(0.06-8.04)\end{array}$ & $\begin{array}{l}0 \cdot 25 \\
(0 \cdot 02-2 \cdot 76)\end{array}$ & $\begin{array}{l}0.18^{*} \\
(0.05-0.66)\end{array}$ \\
\hline $\begin{array}{l}\text { Milk intake } \\
\text { during pregnancy }\end{array}$ & $\begin{array}{l}0.32^{*} \\
(0 \cdot 13-0 \cdot 80)\end{array}$ & $\begin{array}{l}0.13 \\
(0.01-1 \cdot 20)\end{array}$ & $\begin{array}{l}0^{*} \\
(76 / 100)\end{array}$ & $\begin{array}{l}1 \cdot 00 \\
(0 \cdot 29-3 \cdot 50)\end{array}$ \\
\hline \multicolumn{5}{|l|}{ Dental $x$ ray } \\
\hline$>1$ film & $\begin{array}{l}2 \cdot 55^{*} \\
(1.01-6.46)\end{array}$ & $\begin{array}{l}0 \\
(0 / 0)\end{array}$ & $\begin{array}{l}11 \cdot 0^{*} \\
(1 \cdot 27-95 \cdot 5)\end{array}$ & $\begin{array}{l}1 \cdot 50 \\
(0 \cdot 51-4 \cdot 38)\end{array}$ \\
\hline$>2$ & $\begin{array}{l}3 \cdot 14^{*} \\
(1 \cdot 17-8 \cdot 46)\end{array}$ & $\begin{array}{l}0 \\
(0 / 0)\end{array}$ & $\begin{array}{l}\infty * \\
(20 / 0)\end{array}$ & $\begin{array}{l}1 \cdot 71 \\
(0 \cdot 55-5 \cdot 31)\end{array}$ \\
\hline$>4$ & $\begin{array}{l}4 \cdot 00^{*} \\
(1.00-16 \cdot 0)\end{array}$ & $\begin{array}{l}0 \\
(0 / 0)\end{array}$ & $\begin{array}{l}\infty \\
(8 / 0)\end{array}$ & $\begin{array}{l}3.33 \\
(0 \cdot 80-13.9)\end{array}$ \\
\hline $\begin{array}{l}\text { Contact with animals at } \\
\text { time of diagnosis }\end{array}$ & $\begin{array}{l}3 \cdot 50^{*} \\
(1 \cdot 61-7 \cdot 63)\end{array}$ & $\begin{array}{l}6 \cdot 00 \\
(0 \cdot 62-57 \cdot 7)\end{array}$ & $\begin{array}{l}3 \cdot 25 \\
(0 \cdot 93-11 \cdot 3)\end{array}$ & $\begin{array}{l}3 \cdot 20^{*} \\
(1 \cdot 05-9 \cdot 79)\end{array}$ \\
\hline
\end{tabular}


No significant odds ratio ( $p>0.05,63$ triplets) was found for other vaccinations (polio or diphtheriapertussis-tetanus); other infections (varicella, rubella, mumps, etc); other diagnostic radiation (chest, abdomen, upper or lower extremities, spine, head, face, or neck x rays; chest tomography; gastric barium, barium enema, intravenous pyelography, angiocardiography; head, chest, or abdominal CT scan; chest or abdominal echography, etc); maternal problems during pregnancy (alcohol intake, smoking, infectious diseases, drug intake, anaemia, etc); or demographic factors such as parental occupation (classified according to the method of Fabia and Thuy $^{8}$ ) or school careers.

\section{Discussion}

BCG vaccination was found to have a low odds ratio in the 0-2 and the 3-6 year subgroups. However, in the 7-14 subgroup, the odds ratio was not low. In Japan BCG is usually given first at the 3-4 month health examination. However, it is given again compulsorily to tuberculin negative reactors at the entrance of elementary school (at the age of 6 or 7 years). It is conceivable that many patients in the 7-14 year subgroup received BCG at the age of 6 or 7 and that the controls in this subgroup got it earlier.

In Japan hip joint $x$ ray examination is carried out for the purpose of detecting congenital dislocation of the hip, usually on the occasion of the 3-4 month health examination, as with BCG administration. The cross tabulation of BCG vaccination and hip joint $\mathrm{x}$ ray examination revealed that these two factors were closely related to each other in the controls (table 3 ), which may indicate that the controls were given BCG at 3-4 months of age. The non-significant relationship of the two factors in the patient group might be caused by the later administration of BCG to the patients.

Table 3 Relation between $B C G$ and hip joint $x$ ray examination.

\begin{tabular}{lll}
\hline & $\begin{array}{c}B C G \\
(+)\end{array}$ & $(-)$ \\
& & \\
\hline Cases* $^{*}(+)$ & 41 & 8 \\
Hip joint x ray & 11 & 3 \\
Controlst & & 4 \\
Hip joint x ray (+) & 112 & 4 \\
$(-)$ & 6 & \\
\hline$\chi^{2}=0.20(p>0.05)$ & & \\
$+\chi^{2}=20.68(p<0.05)$ & &
\end{tabular}

Live measles vaccine is usually given to 1 year old children. While $73.8 \%$ of the controls were given measles vaccine, only $44.4 \%$ of the cases got it. Measles infection therefore occurred more often in cases $(31.7 \%)$ than in controls $(21 \cdot 4 \%)$. However, it is unlikely to be helpful to consider measles infection and measles vaccination separately. From the point of view of the antigenic stimulation produced by measles virus it seems more reasonable to combine measles and measles vaccination together as a possible protective factor against leukaemia. As shown in table 1, low odds ratios for measles or measles vaccination were found not only in the group as a whole but also in all the age subgroups. Measles is a very common infection, and almost everyone is infected in the course of his life. Therefore, if this disease or its vaccination could prevent the onset of this type of acute lymphoblastic leukaemia, the period before a child is vaccinated or develops measles infection might be a time of increased risk. Hence the earlier a child is infected by particular agents such as BCG or measles virus, the shorter this high risk period may be.

Several other workers have also reported that infectious diseases in the first year of life reduce the risk of acute lymphoblastic leukaemia ${ }^{9}$ or that BCG or other vaccinations reduce the risk of childhood cancer. ${ }^{10-13}$ Since low odds ratios were also found in all age subgroups in relation to atopy, there is a suggestion that immunological mechanisms have something to do with the occurrence or prevention of this disease. It is likely that the non-specific immune surveillance system activated by such events as BCG vaccination may eliminate tumour cells.

Dental $x$ rays for carious teeth had a high odds ratio, especially in the 3-6 year subgroup. Since not many permanent teeth have appeared by this age and since $\mathrm{x}$ ray examinations are not usually done for only mildly affected teeth, the high odds ratio in this subgroup suggests that these films were taken principally for deeply affected carious deciduous teeth. Furthermore, since the odds ratio was not high in the 7-14 year subgroup, where dental $\mathrm{x}$ ray films were done both for decayed permanent teeth and for carious deciduous teeth, it is carious deciduous teeth and the factors related to them that matter. Since no other diagnostic radiation procedure, such as chest $x$ ray, revealed a significant odds ratio, recall bias seems negligible. Moreover, since the onset of acute lymphoblastic leukaemia is sudden and the interval between onset and diagnosis is short, it is hard to imagine that gingival bleeding, which is one of the symptoms of acute leukaemia, prevents teeth brushing and causes dental decay. Several possible causative factors may be reflected in dental $x$ rays: (1) radiation from the $x$ ray itself; (2) inlay metals or some kinds of compounds used in treatment; (3) introduction of agents (eg, bacteria or viruses) through carious deciduous teeth into the body; or (4) eating habits which tend to cause 
carious deciduous teeth. In view of the fact that the peak age of occurrence of acute lymphoblastic leukaemia of this type (between 2 and 6 years $^{3}$ ) coincides with the period when children have deciduous teeth, the relationship between these factors needs to be explored. In future research, direct examination of the oral cavity by dentists is necessary both in cases and in controls.

It is likely that if subtypes of leukaemia vary, the causes will be different. In this study, therefore, strict selection of patients was done so that their immunological nature would be homogeneous. Through such a refinement it is possible to avoid the suppression of significant factors in "noise", and to re-examine the risk factors reported previously. In order to confirm or refute the findings of the present study, research of this kind is required from now on.

The authors thank Drs Hideki Arioka, Nobuyoshi Ishikawa, Mari Endoh, Masahito Ohkawa, Setsuko Ogawa, Yasuhisa Odagawa, Kunio Ozutsumi, Koichi Kikuchi, Tohru Kudoh, Shigeru Kuwajima. Kazuko Koshi, Ryoji Kobayashi, Akira Satake, Satoru Shida, Mutsuo Shibata, Yasuhiro Sugita, Keizo Suzuki, Yutaka Takahashi, Aiko Takase, Takeo Takeda, Shunzo Chiba, Hisaya Nakadate, Michi Nishi, Yoshio Hatae, Kyosuke Hazama, Yukiko Hatayama, Shuzo Matsumoto, and Yoshinori Wagatsuma for their assistance with the collection of the data.

Address for correspondence and reprints: Motoi Nishi MD, Department of Public Health, Sapporo Medical College, S1, W17, Sapporo 060, Japan.

\section{References}

${ }^{1}$ Nadler LM, Korsmeyer SJ, Anderson KC, et al. B cell origin of non-T cell acute lymphoblastic leukaemia. A model for discrete stages of neoplastic and normal pre-B cell differentiation. $J$ Clin Invest 1984; 74: 332-40.

2 Foon KA, Todd RF. Immunologic classification of leukaemia and lymphoma. Blood 1986; 68: 1-31.

${ }^{3}$ Greaves MF. Analysis of the clinical and biological significance of lymphoid phenoptypes in acute leukaemia. Cancer Res 1981; 41: 4752-66.

${ }^{4}$ Kubota H. Children's health and administration. In: Kobayashi N, Tada K, Yabuuchi H, eds. New encyclopedia of pediatrics and related medical sciences: Social pediatrics (vol 26). Tokyo: Nakayama Shoten, 1982: 333-8 (in Japanese).

${ }^{5}$ Mantel N, Haenszel W. Statistical aspects of the analysis of data from retrospective studies of disease. $J$ Natl Cancer Inst 1959; 22: 719-48.

${ }^{6}$ Breslow NE, Day NE. Classical methods of analysis of matched data. In: Breslow NE, Day NE, eds. Statistical methods in cancer research, vol 1 . Lyon: International Agency for Research on Cancer, 1980: 162-89.

${ }^{7}$ Breslow NE, Day NE. Conditional logistic regression for matched sets. In: Breslow NE, Day NE, eds. Statistical methods in cancer research, vol 1. Lyon: International Agency for Research on Cancer, 1980: 248-79.

${ }^{8}$ Fabia J, Thuy TD. Occupation of father at time of birth of children dying of malignant diseases. Br J Prev Soc Med 1974; 28: 98-100.

${ }^{9}$ Van Steensel-Moll HA, Valkenburg HA, Van Zanen GE. Childhood leukaemia and infectious diseases in the first year of life: a register-based case-control study. Am J Epidemiol 1986; 124: 590-4.

${ }^{10}$ Rosenthal SR, Crispen RG, Thorne MG, Piekarski N, Raisys N, Rettig G. BCG vaccination and leukaemia mortality. JAMA 1972; 222: 1543-4.

11 Davignon L, Lemonde P, Robillard P, Frapier A. BCG vaccination and leukaemia mortality. Lancet 1970; ii: 638.

12 Kneale GW, Stewart AM, Wilson LMK. Immunizations against infectious diseases and childhood cancers. Cancer Immunol Immunother 1986; 21: 129-32.

${ }^{13}$ McKinney PA, Cartwright RA, Saiu JMT, et al. The inter-regional epidemiological study of childhood cancer (IRESCC): a case-control study of aetiological factors in leukaemia and lymphoma. Arch Dis Child 1987; 62: 279-87. 